\title{
A OCUPAÇÃO EM JOINVILLE/SC E O PAPEL DA GESTÃO MUNICIPAL PARA MITIGAÇÃO DE DANOS CAUSADOS POR INUNDAÇÕES
}

\author{
Cristiane Regina Muller, Francisco Henrique de Oliveira, Patrícia Royes Schardosim \\ Universidade do Estado de Santa Catarina - UDESC
}

\section{Resumo}

A origem da ocupação no município de Joinville/SC desenvolveu-se na planície do Rio Cachoeira onde as inundações ocorrem tanto pelas cheias do rio quanto pela ação das marés. No entanto, mesmo com o conhecimento desta situação e sendo esta recorrente, o centro urbano do município estruturou-se neste local. Os dados e as informações apresentadas foram adquiridos por meio de pesquisa bibliográfica e no âmbito da Chamada Pública Prevenção de Desastres Naturais $n^{\circ}$ 10/2009 - Fundação de Amparo a Pesquisa e Inovação de Santa Catarina - FAPESC. Com isto o presente trabalho faz uma abordagem ligada a caracterização física, histórica e socioeconômica da área de estudo, bem como avalia os instrumentos de ordenamento territorial que o município dispõe com vistas a mitigar os danos causados pelas constantes inundações.

Palavras-chave: área de risco, ordenamento territorial, inundações.

\begin{abstract}
The source of the occupation in this municipality of Joinville/SC developed on the plain of the Cachoeira River, where the floods occur because the floods of the river and tidal action. However, even knowing about this facts, and this facts be frequent, the urban center oh the municipality was placed in this area. The data and informations displayed in this study are collected by a bibliographical research and in a competence of the public call of Fundação de Amparo a Pesquisa e Tecnologia de Santa Catarina - FAPESC no 010/2009 about Prevention of Natural Disasters. In this way, this present study shows an approach about the characterization of the study area, the occupation origin and the instruments of the territorial planning that municipality has, seeking the mitigation of the damages caused by the constant flooding of the area.
\end{abstract}

Keywords: risk areas, planning territorial, flooding. 


\section{Introdução}

Os desastres naturais estão diretamente vinculados à história do homem e ao seu modo de apropriação e uso dos recursos naturais. Desde a formação dos primeiros agrupamentos humanos até a concepção das cidades modernas, os desastres têm gerado duros impactos à sociedade (MARCELINO, 2008).

A Região Sul do Brasil, bem como a América do Sul, têm sido severamente impactadas por desastres naturais, principalmente a partir da década de 70, o que resultou em grandes prejuízos econômicos, assim como num elevado número de vítimas fatais. A maioria dos desastres está associada às instabilidades severas que causam entre outros, inundações, escorregamentos, vendavais, tornados e aos períodos de déficit hídrico caracterizados pelas estiagens (LACRUZ \& JÚNIOR, 2009).

Em Santa Catarina temos a cidade de Joinville a qual é afetada recorrentemente por inundações, conforme Silveira (2008) as inundações vêm sendo registradas desde a fundação do município, em função da importância econômica que representa, bem como por ser a cidade de maior população no estado, catástrofes desta natureza acarretam grandes prejuízos de cunho econômico e social na região.

Em consonância com outras cidades brasileiras, a ausência de um planejamento territorial efetivo e comprometido com a realidade e a fragilidade ambiental na qual se insere, fez com que a malha urbana decorrente da explosão demográfica de Joinville se expandisse de forma desordenada e, por vezes, em locais não apropriados ao assentamento humano, como margens de rios e encostas.

O presente trabalho apresenta a atual configuração dos instrumentos de ordenamento territorial aplicados a área urbana do município de Joinville, tendo como foco a bacia hidrográfica do Rio Cachoeira, com o intuito de verificar como o amparo legal contribui para a mitigação do processo de inundações. Como aporte as análises utiliza-se técnicas de geoprocessamento, visto que a representação cartográfica tem suma importância neste processo, por permitir a visualização das características gerais e integradoras do estado ambiental, da situação espacial da paisagem, bem como dos instrumentos legais que conduzem o ordenamento territorial da área de estudo.

\section{Problemática da urbanização e bacias hidrográficas}

Os sistemas urbanos são primordialmente áreas de consumo e moradia. Possuem diferentes dimensões ou integração de várias áreas como Regiões Metropolitanas. Em 1900, $13 \%$ da população mundial eram urbanas, atualmente chegam a 50\%, ocupando apenas 2,8\% do território do globo. A população urbana no Brasil chega a 83\% (Tucci, 2008).

O crescimento urbano brasileiro tem sido caracterizado pela expansão irregular da periferia em desacordo com a regulamentação urbana do Plano Diretor e normas urbanísticas. Esta situação dificulta o ordenamento das ações e projetos voltados ao controle ambiental e ordenamento territorial urbano, visto que esta expansão tem geralmente caráter irregular.

É fato que a população cresceu e foi se instalando de forma desordenada, invadindo as margens da calha fluvial, antes reservadas apenas ao escoamento dos cursos d'água e a diversidade natural. Agora, as águas pluviais não estão sendo interceptadas pela vegetação, os escoamentos superficiais não mais encontram as condições propícias para infiltração, nem tampouco os espaços que outrora se acomodavam para cumprir sua função na natureza. 
De acordo com Filho \& Medeiros (2004) toda a infraestrutura urbana é afetada pelo processo de urbanização, e em particular a estrutura voltada aos recursos hídricos (sistema de esgotamento sanitário, sistema de abastecimento de água, resíduos sólidos e sistema pluvial), gerando impactos de natureza diversa (sociais, econômicos e ambientais) em função do gerenciamento inadequado da água.

Além destes, a maneira como a ocupação do espaço vem sendo realizada, desconsiderando muitas vezes as características do ambiente, tem ocasionado muitos transtornos, como as cheias urbanas e o aumento significativo na frequência das inundações.

A tendência da urbanização é de ocorrer no sentido de jusante (águas abaixo) para montante (águas acima), na drenagem urbana, devido as características de relevo. Quando um loteamento é projetado, o município exige apenas que o projeto de esgoto pluvial seja eficiente no sentido de drenar a água do loteamento, mas não avalia qual é o impacto sobre o restante da rede de drenagem a jusante (águas abaixo). O somatório da impermeabilização dos vários loteamentos produz aumento da frequência e magnitude das enchentes rio abaixo.

A combinação destes processos (urbanização sem planejamento e a crescente impermeabilização do solo) conduz a picos de vazão cada vez mais difíceis de controlar mediante as intervenções estruturais tradicionais, voltadas à ampliação das capacidades de escoamento superficial, o que tem aumentado sensivelmente o benefício tanto de dispositivos de detenção, como de medidas não-estruturais de caráter essencialmente preventivo, visando o convívio com estes eventos.

As limitações das ações públicas atuais, em muitas cidades brasileiras, estão indevidamente voltadas para medidas estruturais com visão pontual. A canalização tem sido extensamente usada para transferir a enchente de um ponto a outro na bacia, sem que sejam avaliados os efeitos da jusante ou os reais benefícios destas obras.

Com isto o prejuízo público é dobrado, já que, além de não resolver o problema, os recursos são gastos de forma equivocada. Esta situação é decorrente, na maioria das cidades, do seguinte: da falta de considerar o planejamento da rede cloacal e pluvial e da ocupação das áreas de risco, quando se formulam os Planos Diretores; o gerenciamento inadequado da implantação das obras públicas e privadas no ambiente.

\section{3. Área de Estudo}

\subsection{Município de Joinville}

O município de Joinville, localizado entre as coordenadas $26^{\circ} 18^{\prime} 05^{\prime} \mathrm{S} / 48^{\circ} 50^{\prime} 38^{\prime \prime} \mathrm{W}$ e 26²8'50"S/48 43'08'W possui uma área de $1.146,873 \mathrm{~km}^{2}$ e 515.288 habitantes ${ }^{1}$, que estão divididos em 38 bairros, 01 distrito (Pirabeiraba) e 02 zonas industriais (Norte e Tupy).

Localizada na região Sul do país, Joinville desenvolveu-se num ambiente entre as escarpas da Serra do Mar e o Oceano Atlântico, onde existe a presença de vales encaixados e profundos e uma planície resultante de processos de sedimentação costeira.

Joinville é a maior cidade catarinense, sendo responsável por aproximadamente $20 \%$ das exportações catarinenses. É também o $3^{\circ}$ pólo industrial da região Sul, com volume de receitas geradas aos cofres públicos inferior apenas às capitais Porto Alegre (RS) e Curitiba (PR). A cidade concentra grande parte da atividade econômica na indústria, com destaque para os setores metal mecânico, têxtil, plástico, metalúrgico, químico e farmacêutico (IPPUJ, 2009 ).

\footnotetext{
${ }^{1}$ Dados do Censo de 2010 - IBGE.
} 


\subsection{Histórico de ocupação}

A história de Joinville inicia com o casamento do príncipe Felipe de Joinville, (filho do rei da França) com a irmã de Dom Pedro II, a princesa Francisca Carolina. Terras da Província de Santa Catarina, fronteiras à Ilha de São Francisco, foram dadas ao príncipe como complemento do dote. Neste local assentou-se a ocupação da Colônia Dona Francisca, a qual deu origem ao município de Joinville (FICKER, 1965).

Rocha (1997) explica o surgimento da ocupação da seguinte forma:

Devido a problemas financeiros, o príncipe decidiu negociar as suas terras para colonização e assinou um contrato com o armador e senador alemão, Christian Mathias Schroeder (em Hamburgo). A intenção era formar uma comunidade agrícola modelo na América do Sul, com orientação capitalista [...] Na verdade, vocação agrícola em Joinville houve muito pouco, pois o planejamento em escritórios na Alemanha não considerou as dificuldades locais para o êxito da agricultura, como a densa floresta a ser derrubada e os terrenos pantanosos com formação de manguezais [...] (ROCHA, 1997, p.22).

Um dos fatores determinantes para a vinda dos imigrantes alemães foi o fato da Alemanha dispor de contingente para migrar, em virtude do processo de industrialização e das tensões sociais e políticas que estavam ocorrendo na região. Estas pessoas buscavam por novas oportunidades de vida, principalmente em decorrência das injustiças sociais, divergências políticas, guerras, impostos altos e rápido crescimento da população (Rocha, 1997). Neste contexto, formou-se a Sociedade Colonizadora de 1849 em Hamburgo, que mandou para o Brasil o primeiro contingente de emigrantes.

A Colônia compreendia uma área total de 45.582 hectares. Dentre as questões legais envolvidas neste processo, aos colonos era assegurado, pelo prazo de dez anos, a isenção de serviço militar e de direitos alfandegários, e também impunha à Companhia Colonizadora a obrigação de zelar pela saúde dos doentes e assegurar educação as crianças. Foram 191 os primeiros povoadores da nova Colônia, dos quais 117 alemães e suíços, vindos de Hamburgo e os demais noruegueses. Nem todos os imigrantes permaneceram na colônia recém criada, muitos dos que abandonaram estão entre os primeiros noruegueses chegados ao local (IPPUJ, 2011, p.7).

Em função da necessidade de comunicação marítima, os imigrantes estabeleceram-se na região mais próxima do porto de São Francisco, que abrigava grandes navios. Desta forma, foi ocupada a área do ribeirão Matias, o pequeno tributário do Rio Cachoeira, pois esta desviava dos banhados do Rio Itapocu e da Lagoa Bonita, sendo, portanto, a terra elevada mais próxima do porto de São Francisco (PELUSO, 1991).

Silveira (2009) cita que o estabelecimento da Colônia ficou sob responsabilidade do engenheiro alemão Guenther e que o núcleo da Colônia não foi fixado em função da salubridade do local, pois na época não passava de um lodaçal. A escolha do local levou em consideração o acesso facilitado à Colônia bem como o melhor escoamento da produção do Planalto em direção aos portos, nesse caso, o de São Francisco do Sul, cuja exportação se destinava à Europa e à região do "Prata" (IPPUJ, 2011, apud. Santanna, 1996).

Como o sítio escolhido para o estabelecimento era muito úmido, um dos primeiros cuidados do dirigente da colônia foi a abertura de valetas de drenagem (IPPUJ, 2009). Entende-se que a região não era favorável a fundação de um núcleo urbano, mas a importante função comercial do porto orientou a escolha do local e facilitou a consolidação da ocupação. 
Nas primeiras décadas de ocupação da Colônia Dona Francisca, a precipitação das chuvas era bastante elevada, conforme consta nas anotações feitas por Johan Paul Schmalz (IPPUJ, 2009, p.31), fato este também derivado da orografia em virtude da presença da Serra do Mar.

O padrão colonial de ocupação do solo de Joinville começou a ser modificado na medida em que a atividade agrícola mostrou-se inviável para o sucesso do empreendimento (Colônia Dona Francisca), ocorrendo em virtude disto uma evasão de mão-de-obra. Joinville assistiu uma notável expansão urbana a partir da década de 50 com ampliações sucessivas do perímetro urbano que invadiram áreas tradicionalmente voltadas a agricultura, provocando declínio desta atividade e gerando imensos vazios urbanos (JOINVILLE, 1987).

Esta expansão urbana pode ser visualizada quando comparamos o padrão de evolução da população residente na área urbana e rural do município, Quadro 1.

Quadro 1 - Evolução da população de Joinville/SC.

\begin{tabular}{|c|c|c|c|}
\cline { 2 - 4 } \multicolumn{1}{c|}{} & \multicolumn{3}{c|}{ População residente } \\
\hline Ano & Total & \% Urbana & \% Rural \\
\hline 1940 & 30.000 & 55,75 & 43,72 \\
\hline 1950 & 43.334 & 49,36 & 50,64 \\
\hline 1960 & 70.687 & 78,56 & 21,69 \\
\hline 1970 & 120.559 & 93,40 & 11,57 \\
\hline 1980 & 235.812 & 94,26 & 5,74 \\
\hline 2000 & 429.604 & 96,60 & 3,40 \\
\hline 2010 & 515.250 & 96,54 & 3,38 \\
\hline
\end{tabular}

Fonte: IBGE (2011), JOINVILLE (1987) e JOINVILLE (2009).

Visualiza-se até a década de 50 o equilíbrio entre a distribuição da população residente na área urbana a e rural em Joinville, contudo a partir da década de 60 há a marcante diferenciação da distribuição desta população estando predominantemente na área urbana do município, chegando atualmente a $96,54 \%$ da população total.

O desenvolvimento do município foi baseado no setor industrial, o qual emprega mão de obra predominantemente de baixa renda, fato este que refletiu na configuração do espaço urbano, determinando uma paisagem urbana singular na qual o baixo gabarito construtivo, com a imagem de cidade horizontal vem mudando apenas recentemente (JOINVILLE, 1987).

$\mathrm{Na}$ trajetória da Indústria em Joinville, enquanto força motriz da expansão urbana, dois casos de extrema importância ocorreram. A primeira referência se faz a Fundição Tupy, cuja transferência do seu parque industrial do núcleo central para o bairro Boa Vista, em 1954, contribuiu para o adensamento e cristalização de grande parte dos bairros da Zona Leste, na condição de Fonte geradora de empregos. Como segunda referência, tem-se no Distrito Industrial, criado em 1973 pelos governos municipal e estadual, uma tentativa de organizar a expansão do setor industrial (IPPUJ, 2011). 


\subsection{Bacia hidrográfica do Rio Cachoeira - Joinville/SC}

A bacia hidrográfica do Rio Cachoeira está totalmente inserida na área urbana de Joinville e sua foz está na baía da Babitonga, a qual se liga ao oceano atlântico, Figura 1. Drena uma área de $83,12 \mathrm{~km}^{2}$, que representa $7,3 \%$ da área do município. Apesar de apresentar uma área de contribuição pequena, as inundações na bacia são condicionadas por outros aspectos, tal como as chuvas abundantes e regulares na região.

Esta bacia está situada nos Domínios Morfoestruturais dos Depósitos Sedimentares Quaternários, na Unidade Geomorfológica correspondente a Planície Costeira, ou Planície Quaternária, formada pela sedimentação flúvio-marinha (KNIE, 2002). Encontra-se inserida em dois grandes compartimentos de relevo: o de dissecação em colinas, morros e montanhas, modelados em rochas cristalinas antigas, e o de acumulação, modelado em sedimentos recentes de origem marinha, lacustre, coluvionar e fluvial.

\section{Figura 1 - Mapa de localização da Bacia Hidrográfica do Rio Cachoeira - Joinville/SC.}

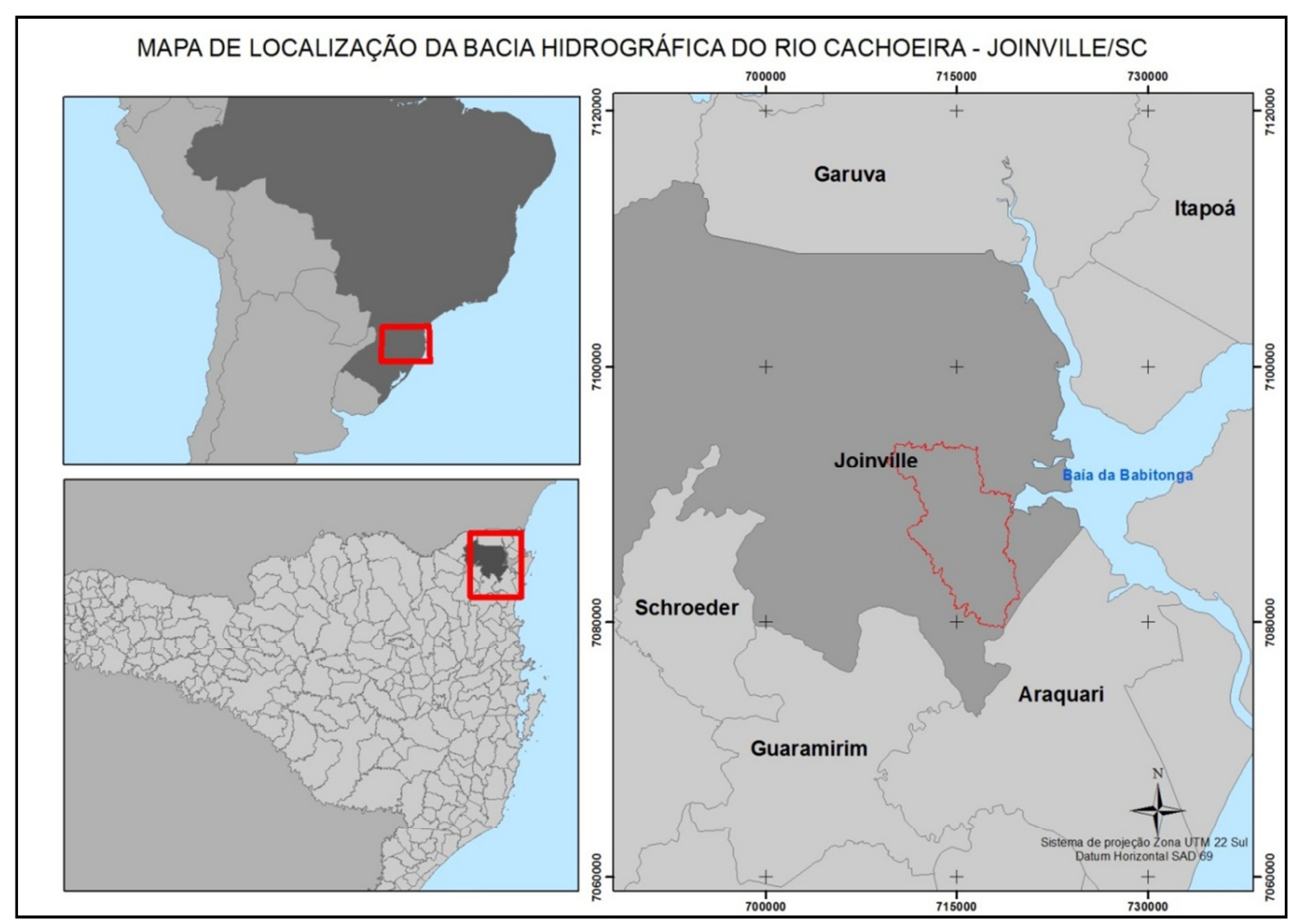

As feições do modelado de acumulação se configuram em planícies e terraços. Nas planícies, encontram-se rios meandrantes, porém muitos segmentos já foram canalizados em função do processo de urbanização.

Em relação aos solos predominantes na Bacia do Rio Cachoeira encontram-se cinco classes distintas: Cambissolo Flúvico, Cambissolo Háplico , Gleissolo Háplico, Argissolo Amarelo e o Neossolo Litólico. Os dois primeiros ocorrem com predominância em relação aos demais e estão nas áreas nas quais a urbanização se desenvolveu com maior notoriedade. O Argissolo Amarelo e o Neossolo Litólico tem sua ocorrência relacionada as áreas que possuem topografia mais acentuada. Os Gleissolos correspondem aos solos localizados em áreas de relevo praticamente plano (planícies aluviais e várzeas), margeando os rios, caracteriza-se por ser um solo hidromórfico, mal drenado, pouco profundo, distrófico ou 
eutrófico, dependendo da natureza do material sobre o qual se desenvolveram (GUERRA \& BOTELHO, 2001). As áreas de ocorrência deste solo são áreas sujeitas a inundações, pois são baixas e possuem o lençol freático próximo da superfície.

Há também a presença dos solos indiscriminados de mangue, que se caracterizam por serem terrenos halomórficos, alagados, localizados junto a desembocaduras dos rios, nas reentrâncias da costa e nas margens de lagoas diretamente afetadas pela influência das marés.

O clima na qual esta área está inserida é o subtropical úmido, fortemente marcado por duas estações bem distintas durante o ano: o verão e o inverno. Os totais pluviométricos anuais no município de Joinville estão entre 1900-2500 mm.

A foz encontra-se numa região estuarina sob a influência das marés, onde se encontram remanescentes de manguezais. Durante os períodos de amplitude da maré, pode-se verificar a inversão do fluxo da água do rio (remanso) até quase a metade de seu percurso causado pelo ingresso de água salgada através do canal (IPPUJ, 2009).

As baixas altitudes junto a foz, associadas ao efeito das marés astronômicas e metereológicas, e das precipitações pluviométricas, causam freqüentes problemas de inundações na região central, atingindo também alguns afluentes, principalmente (IPPUJ, 2009).

Foi nessa região de planície que se desenvolveu com mais intensidade a ocupação humana, próxima aos manguezais. A combinação dos fatores de clima, vegetação e relevo proporcionam um forte intemperismo químico que resulta num solo bastante sensível e instável, de matriz argilosa (IPPUJ, 2009).

Atualmente, a impermeabilização do solo na bacia do Rio Cachoeira é de, aproximadamente, $55 \%$ de sua área total, concentrando-se nas áreas nas áreas de menor declividade e, consequentemente, mais suscetíveis aos fenômenos de inundação, recorrentes nesta área.

\subsection{Instrumentos de Ordenamento Territorial Municipais}

Desde a sua fundação, em 1851, Joinville enfrenta recorrentes cheias que acarretam graves problemas para a região. Inicialmente os colonizadores, buscando achar solução para a situação da instalação em terrenos alagadiços, providenciaram a abertura de valetas para drenagem das águas (IPPUJ, 2009). Com o passar dos anos e a estruturação do poder público municipal, surgiram diversas iniciativas com o intuito de mitigar situações de desastres ocasionadas pelo extravasamento das cheias do Rio Cachoeira.

O primeiro trabalho produzido com caráter de ordenamento do território joinvillense foi o Plano Básico de Urbanismo (PBU), realizado em 1965 pelo Escritório Jorge Wilheim Arquitetos Associados em parceria com a empresa Sociedade SERETE de Estudos e Projetos Ltda., sediada em São Paulo. Cabe ressaltar que a elaboração deste instrumento de ordenamento territorial coincide com a época em que as sucessivas modificações do perímetro urbano e crescimento populacional levaram a predominância da população residente em área urbana a rural $(78,56 \%$ população residindo em área urbana na década de 60$)$, levando a modificações da infraestrutura existente e conseqüente necessidade de desenvolvimento de novos instrumentos de gestão do território.

Dentre os objetivos do Plano Básico de Urbanismo, constava a execução do Plano Diretor e a proposta de medidas jurídico-legislativas que permitissem a adequada execução do planejamento, orientando a expansão urbana e impedindo o agravamento eventual de problemas passíveis de acarretar ônus futuros ao município (SOUZA, 2005). 
Na década seguinte foi elaborado o "Plano Diretor de 73", primeiro plano diretor do município, o qual já retratava a densa ocupação na região da bacia do Rio Cachoeira através da execução de um mapa de zoneamento na escala de 1:20.000. Posteriormente, durante os anos de 1980, diversas leis complementares e decretos foram aprovados no sentido de aprimorar este primeiro trabalho.

Em 1987 a Secretaria de Planejamento desenvolveu o Plano de Estruturação Urbana (PEU), um documento de grande valor para a gestão do município, incluindo aí o risco a desastres naturais, que demonstrou por meio de mapas temáticos, como os mapas de "Deficiências do Sistema Físico-Natural", "Macrozoneamento de Usos do Solo", "Evolução Urbana", "Habitação" (todos com escala de 1:50.000), as especificidades físicas e de desenvolvimento da região, demonstrando, inclusive, as áreas susceptíveis a alagamentos e os vetores de pressão urbana. Este plano analisou a morfologia e distribuição espacial das atividades econômicas, resgate histórico da evolução da malha urbana e a forma como a cidade se organiza. Dentre as questões ambientais citadas pelo PEU está a problemática da necessidade de aterros para tornar áreas próprias a habitação condicionando a exploração dos morros do município através de cortes sem critérios técnicos.

Dentre outros encaminhamentos, enquanto recomendação este documento sugere a criação de mecanismos que impeçam/restrinjam a ocupação das áreas sujeitas a inundação (JOINVILLE, 1987), do mesmo modo que estimula a verticalização e adensamento populacional da área central em virtude de ser bem estruturada em termos de serviços e estruturas públicas.

Com a criação da Fundação Instituto de Pesquisa e Planejamento Urbano - IPPUJ, em 1991, surgiu um órgão específico para suporte a assuntos governamentais voltados para o desenvolvimento físico-territorial. Em 1996, novas leis complementares substituíram a legislação de 1973, contribuindo para o desenvolvimento do planejamento e ordenamento territorial municipal através da apresentação de novos mapas de zoneamento.

Tem-se, atualmente vigente, a Lei Complementar $n^{\circ} 312 / 2010$, que altera e dá nova redação à Lei Complementar $n^{\circ}$ 27/96, atualizando as normas de parcelamento, uso e ocupação do solo no município de Joinville/SC. Contudo, a concepção de destinação dos usos de cada área tem seu fundamento na Lei Complementar 261/08, que diz respeito ao Plano Diretor Sustentável deste município. Neste dispositivo legal a área urbana do município, na qual insere-se a bacia hidrográfica do Rio Cachoeira, está, conforme Artigo 64, subdividida com as seguintes macrozonas:

- I - Área Urbana de Adensamento Prioritário (AUAP) - são as regiões que não apresentam fragilidade ambiental, possuem boas condições de infraestrutura, sistema viário estruturado, transporte coletivo, equipamentos públicos comprovadamente capazes de absorver a quantidade de moradores desejada, maior volume de atividades voltadas ao setor terciário de baixo impacto e grande número de vazios urbanos;

- II - Área Urbana de Adensamento Secundário (AUAS) - são as regiões que não apresentam fragilidade ambiental, possuem boas condições de infra-estrutura, sistema viário estruturado, transporte coletivo, equipamentos públicos comprovadamente capazes de absorver a quantidade de moradores desejada, maior volume de atividades voltadas ao setor terciário com possibilidade de absorver atividades ligadas ao setor secundário de baixo impacto e vazios urbanos;

III - Área Urbana de Adensamento Especial (AUAE) - são as regiões que não apresentam fragilidade ambiental, possuem boas condições de infraestrutura, sistema viário estruturado, transporte coletivo, equipamentos públicos comprovadamente capazes de 
absorver a quantidade de moradores desejada porém apresentam características paisagísticas e históricas e/ou predominância de residências unifamiliares, não sendo recomendáveis para o adensamento populacional pleno;

- $\quad$ IV - Área Urbana de Adensamento Controlado (AUAC) - são as regiões que apresentam eventuais fragilidades ambientais, possuam mínimas condições de infra-estrutura, impossibilidades para a melhoria do sistema viário, deficiência de acesso ao transporte coletivo, aos equipamentos públicos e serviços essenciais e que não reunam condições de absorver uma quantidade maior de moradores ou de atividades econômicas;

- V - Área Urbana de Proteção Ambiental (AUPA) - são as regiões que apresentam grandes fragilidades ambientais, caracterizando-se por áreas acima da cota 40, áreas de mananciais de água, margens de rios e manguezais e áreas verdes consideradas reservas paisagísticas, que necessitam de grandes restrições de ocupação para efetiva proteção, recuperação e manutenção.

Dentre os objetivos do Plano Diretor Sustentável consta a preocupação em prevenir situações de desastres através do reconhecimento e monitoramento dos aspectos físicos do município. No artigo 24 está relatado como objetivo o seguinte:

II - identificar, cadastrar, fiscalizar e coibir a ocupação de áreas de risco comprovadas, faixas marginais de rios e lagoas, rodovias e áreas de proteção ambiental, considerando as normas ambientais aplicáveis bem como as resoluções dos Comitês de Bacias Hidrográficas;

\section{[...]}

IV - apoiar e fortalecer a defesa civil, prevendo a criação de órgão específico e do Sistema de Informações Geográficas - SIG, visando incentivar a adoção de medidas preventivas contra desastres e catástrofes de qualquer natureza, tais como:

Os efeitos de enchentes, desmoronamentos e outras situações de risco; [...] (JOINVILLE, 2008).

O atual Plano Diretor propõe ainda, em seu artigo 137, a criação do Sistema de Informações Municipais, um instrumento que permite o processo de avaliação contínua do desenvolvimento sustentável municipal através de indicadores de desempenho atualizados constantemente ${ }^{2}$.

Outro instrumento de ordenamento territorial importante que vem sendo desenvolvido no município diz respeito ao Plano Diretor de Drenagem Urbana - PDDU -, com vistas a identificar pontos críticos para intervenção, bem como soluções objetivando a mitigação dos efeitos dos eventos de inundação recorrentes.

\section{Método}

O método aplicado para o cruzamento de informações em um ambiente SIG utiliza os pressupostos de Xavier (2001) o qual cita que a aplicação de técnicas de geoprocessamento é extremamente útil para o planejamento municipal, uma vez que processamento e sobreposição de mapas/atributos proporciona a visualização e entendimento de conceitos ambientais e sócio-econômicos altamente relevantes para entendimento do espaço que está sendo analisado.

\footnotetext{
${ }^{2}$ Informações disponíveis para consulta no seguinte endereço: http://geoprocessamento.joinville.sc.gov.br/
} 
Estes sistemas são capazes de expressar eficientemente, conceitos de expressão territorial tais como: "unidades potenciais de uso da terra", "zonas de influência", "áreas críticas", "centros dinâmicos de poder", entre outros, com isto esta tecnologia tem a capacidade de prestar serviços valiosos para o planejamento geoeconômico, para a proteção ambiental e, em nível mais alto, para a análise geopolítica.

Para sistematizar a aplicação dos métodos no desenvolvimento deste trabalho foi gerado um fluxograma, Figura 4, apresentando as etapas desenvolvidas.

Figura 4 - Fluxograma ilustrativo das etapas do desenvolvimento trabalho.

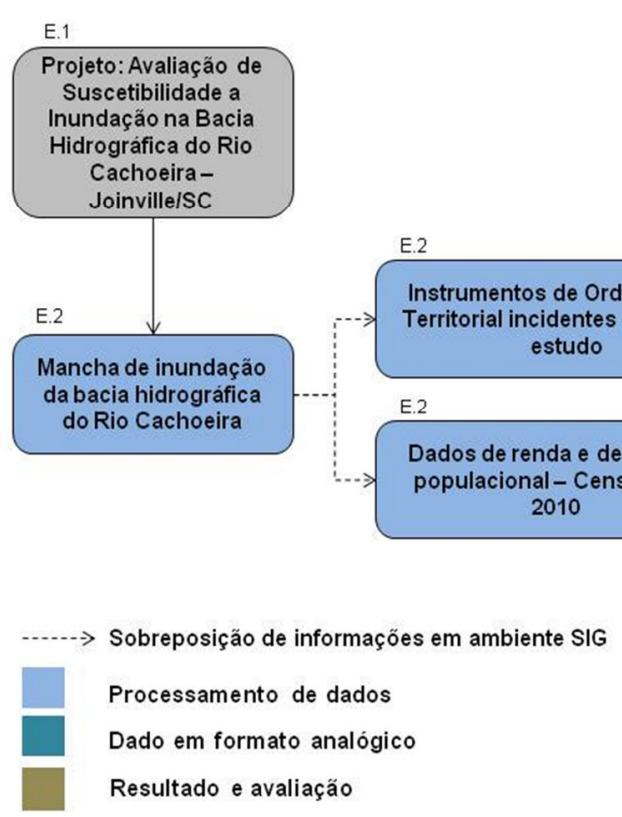

Para construção do embasamento teórico foi procedido levantamento dos dados e instrumentos de ordenamento territorial incidentes na área de estudo junto a Prefeitura Municipal de Joinville, bem como consulta a base de dados do IBGE relacionada aos dados dos setores censitários da área de estudo. Cumpre informar que o presente trabalho foi desenvolvido no âmbito do projeto de pesquisa fomentado pela Fundação de Amparo a Pesquisa e Inovação no Estado de Santa Catarina - FAPESC -, o qual avaliou a suscetibilidade a inundação na bacia hidrográfica do Rio Cachoeira - Joinville/SC, desta forma os dados referentes à suscetibilidade a inundação aplicados nesta pesquisa são oriundos desta pesquisa (etapa E.1).

O desenvolvimento da etapa E. 2 refere-se a entrada de dados no SIG. Elaborou-se uma base de dados georreferenciada contanto com as seguintes informações temáticas:

- $\quad$ Base cartográfica municipal, escala 1:1000, 2007;

- Mancha de suscetibilidade a inundação da bacia hidrográfica do Rio Cachoeira;

- $\quad$ Renda mensal por domicílio elaborado com os dados do Censo 2010;

- $\quad$ Lei 312/2010, que estabelece o as diretrizes de parcelamento e uso e ocupação do solo no município de Joinville/SC,

- $\quad$ Lei Complementar 261/08, que trata do Plano Diretor Sustentável de Joinville.

A estruturação do SIG para sobreposição e análise dos dados foi procedida através da utilização do aplicativo da plataforma ESRI, ArcGIS 10. 
Na etapa E.3 e E.4 realizou-se a avaliação da sobreposição da mancha de inundação ao mapa de renda, com vistas a caracterizar a população que reside nas áreas suscetíveis a ocorrência de inundação. Fez-se ainda o cruzamento de dados junto aos mapas constantes na Lei 261/2008, referente ao Plano Diretor Sustentável de Joinville/SC e Lei Complementar $\mathrm{n}^{\circ}$ 312/2010, que estabeleceu diretrizes para o parcelamento e uso e ocupação do solo em Joinville/SC. Desta forma buscou-se avaliar a destinação que é dada para estas áreas bem como a presença de instrumentos com vistas a mitigar a ocorrência destes eventos.

\section{Resultados}

O cruzamento de dados em ambiente SIG resultou na identificação de características referentes a configuração socioeconômica da população inserida nas áreas suscetíveis a inundação. A Figura 5 e o Quadro 2 apresentam o rendimento mensal médio dos domicílios localizados em áreas suscetíveis à inundação na bacia hidrográfica do Rio Cachoeira. 
Figura 5 - Sobreposição da mancha de inundação aos dados de renda dos bairros da bacia hidrográfica do Rio Cachoeira - Joinville/SC.

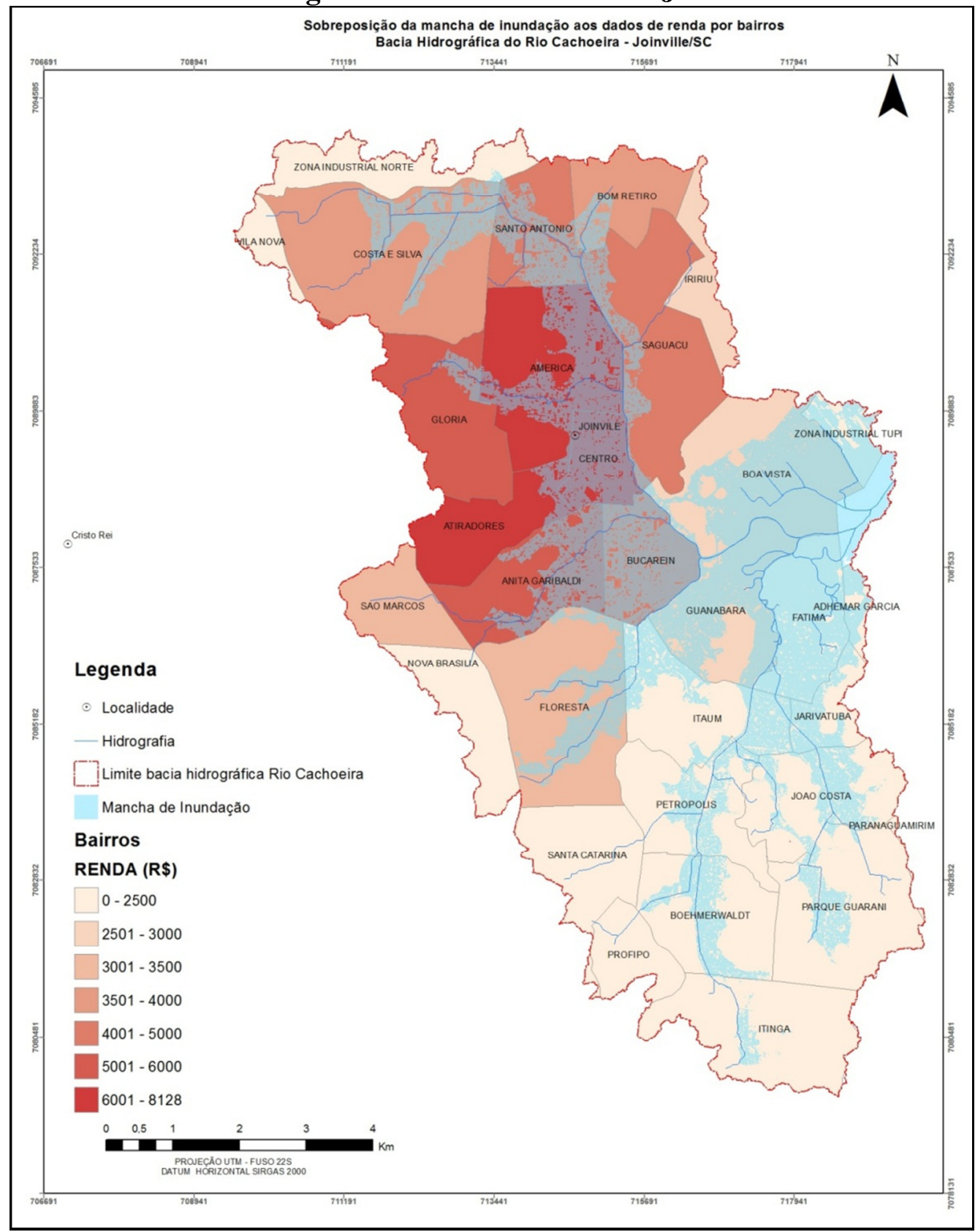

O cruzamento de informações apresenta o indicativo que 07 dos 23 bairros inseridos em áreas suscetíveis a ocorrência de inundação possuem comprometimento superior a $50 \%$ de suas áreas $\left(\mathrm{m}^{2}\right)$ inseridas em áreas de fragilidade ambiental.

Outra informação importante diz respeito a renda da população residente nestas áreas, o Gráfico 1 apresenta a distribuição de renda por bairros da bacia hidrográfica do Rio Cachoeira inseridos em áreas de suscetibilidade a inundação, no qual visualiza-se que alguns destes, 11 (onze) primeiros apresentados no gráfico, possuem renda superior a média do município de Joinville/SC. As maiores rendas da área de estudo são, respectivamente, dos bairros: Atiradores, Centro e América. 
Quadro 2 - Sobreposição das áreas de suscetibilidade a inundação aos dados de Renda e Zoneamento do município de Joinville/SC.

\begin{tabular}{|c|c|c|c|c|c|}
\hline Bairro & $\begin{array}{c}\text { Área } \\
\text { suscetível a } \\
\text { inundação }\end{array}$ & $\begin{array}{c}\text { Renda } \\
(\mathbf{R} \$)\end{array}$ & Bairro & $\begin{array}{c}\text { Área } \\
\text { suscetível a } \\
\text { inundação }\end{array}$ & $\begin{array}{c}\text { Renda } \\
(\mathbf{R} \$)\end{array}$ \\
\hline Fatima & $95 \%$ & 2021,33 & João Costa & $31 \%$ & 2199,84 \\
\hline Centro & $91 \%$ & 7117,91 & Boehmerwald & $28 \%$ & 2218,26 \\
\hline Bucarein & $89 \%$ & 4913,55 & Petrópolis & $25 \%$ & 2267,46 \\
\hline $\begin{array}{l}\text { Zona Industrial } \\
\text { Tupy }\end{array}$ & $82 \%$ & 2463,79 & Floresta & $24 \%$ & 3349,56 \\
\hline Guanabara & $76 \%$ & 2915,48 & Costa e Silva & $21 \%$ & 3503,11 \\
\hline Adhemar Garcia & $68 \%$ & 2341,57 & Saguaçu & $15 \%$ & 4688,46 \\
\hline Boa Vista & $65 \%$ & 2829,04 & Bom Retiro & $15 \%$ & 3673,30 \\
\hline Jarivatuba & $53 \%$ & 2042,31 & Parque Guarani & $13 \%$ & 2075,64 \\
\hline Anita Garibaldi & $46 \%$ & 5465,36 & Atiradores & $10 \%$ & 8127,86 \\
\hline Santo Antônio & $45 \%$ & 4790,57 & Gloria & $6 \%$ & 5508,15 \\
\hline América & $44 \%$ & 7009,27 & Itinga & $5 \%$ & 2123,16 \\
\hline Itaum & $43 \%$ & 2495,31 & $\begin{array}{l}\text { Zona Industrial } \\
\text { Norte }\end{array}$ & $1 \%$ & 1880,76 \\
\hline \multicolumn{5}{|c|}{ Média de Renda do Município de Joinville } & $2.853,24$ \\
\hline
\end{tabular}


Gráfico 1 - Rendimento mensal médio dos domicílios (IBGE, 2010), agrupados por bairro, e localizados em áreas suscetíveis a inundação na bacia hidrográfica do Rio Cachoeira - Joinville/SC.

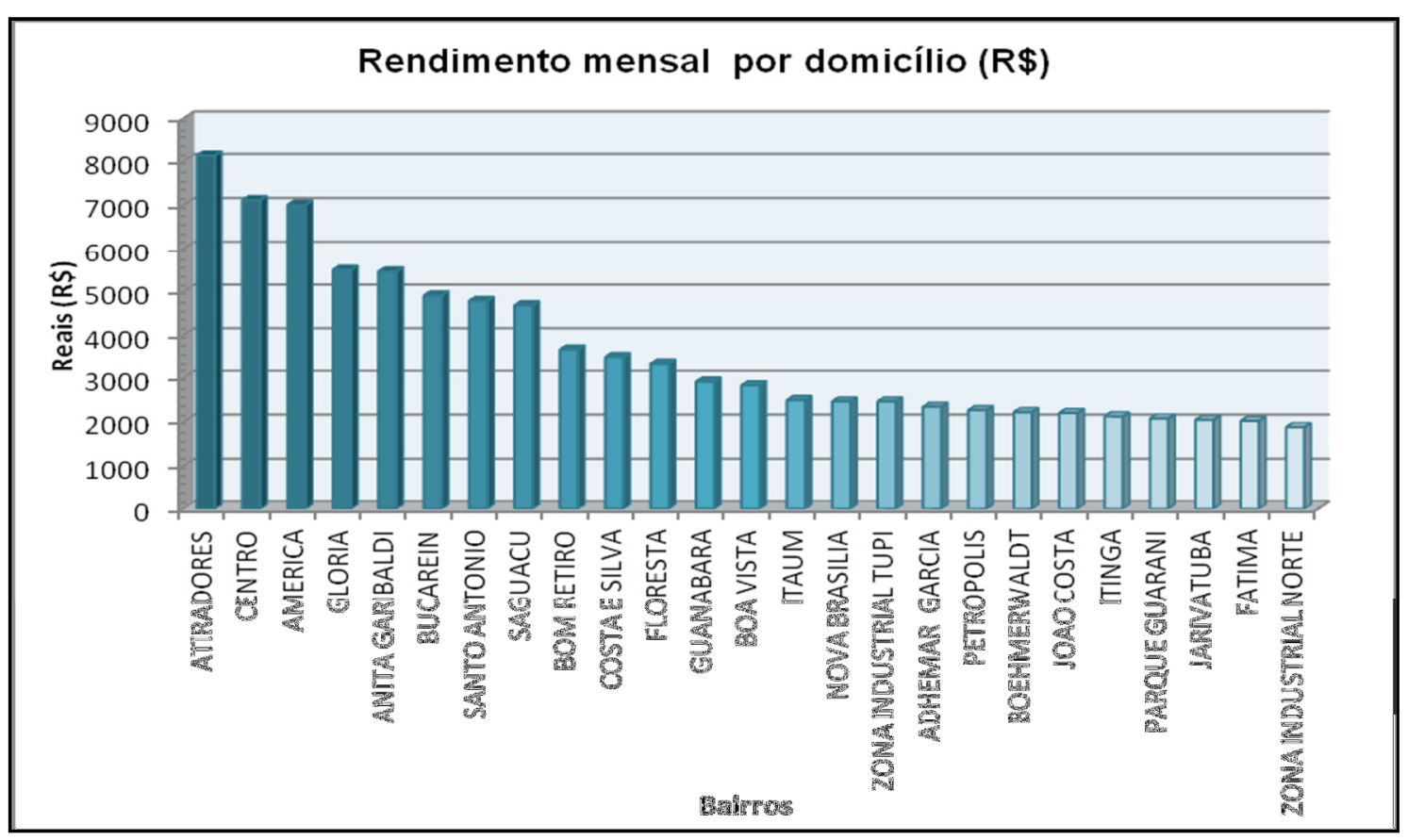

O nível de renda mais elevado da população residente neste local está ligado a gênese da formação do município de Joinville/SC que ali estabeleceu seu núcleo de colonização e comercialização. A evolução urbana do município apresenta que o parcelamento do solo evolui no entorno de um núcleo central, sendo estes os que apresentam, atualmente, a maior renda do município.

Esta gênese de ocupação está atrelada à formação histórica das cidades brasileiras, nas quais a população buscava ocupar as áreas planas da cidade, comumente próximas a cursos de água para transporte e escoamento da produção. Devido a esse modo de ocupação parte da população hoje se encontra sobre sítios em condições desfavoráveis ao assentamento humano, como áreas susceptíveis a inundação.

O bairro de Joinville denominado Centro, com renda mensal de 14 salários mínimos ${ }^{3}$, constitui um dos bairros mais susceptíveis a inundação, possuindo $91 \%$ da sua área inserida em suscetibilidade muito alta ao acontecimento deste fenômeno. A ocorrência de inundações neste bairro é altamente prejudicial, visto que afeta não apenas seus moradores, há também a população de menor renda que habita outros bairros do município e que devido à existência e concentração das atividades do comércio e prestação de serviços, tem ali seu local de trabalho, podendo ser diretamente afetada por ocasião destes estabelecimentos encerrarem/paralisarem suas atividades devido aos prejuízos provocados pelas inundações.

Caso semelhante ocorre em relação a Zona Industrial Tupy, que constitui-se pela gleba de $1.208 .000 \mathrm{~m}^{2}$ localizada no bairro Boa Vista (IPPUJ, 2011), e possui $82 \%$ de sua área inserida em área de suscetibilidade a inundação, sendo a ocorrência destes eventos sentida não apenas localmente, mas também junto a população que tem sua colocação profissional nesta área. Em contraponto, tem-se a Zona Industrial Norte de Joinville, a qual possui apenas 1\% se sua área total classificada como suscetível a inundação constituindo, do ponto de vista de

\footnotetext{
${ }^{3}$ Cálculo baseado no salário mínimo vigente no ano de 2010 (R\$ 510,00), de acordo com a Lei 12255/2010.
} 
fragilidades ambientais ligadas a estes eventos, ambiente mais adequado ao assentamento deste segmento de atividades, visto sua importância socioeconômica ao município.

O Detalhamento do cruzamento das informações de suscetibilidade a inundação junto aos dados constantes na Lei Complementar $\mathrm{n}^{\circ} 312$ /2010, que estabelece diretrizes para o parcelamento e uso e ocupação do solo em Joinville/SC, é apresentado no Gráfico 2.

Gráfico 2 - Zonas inseridas em área de suscetibilidade a inundação na bacia hidrográfica do Rio Cachoeira -Joinville/SC.

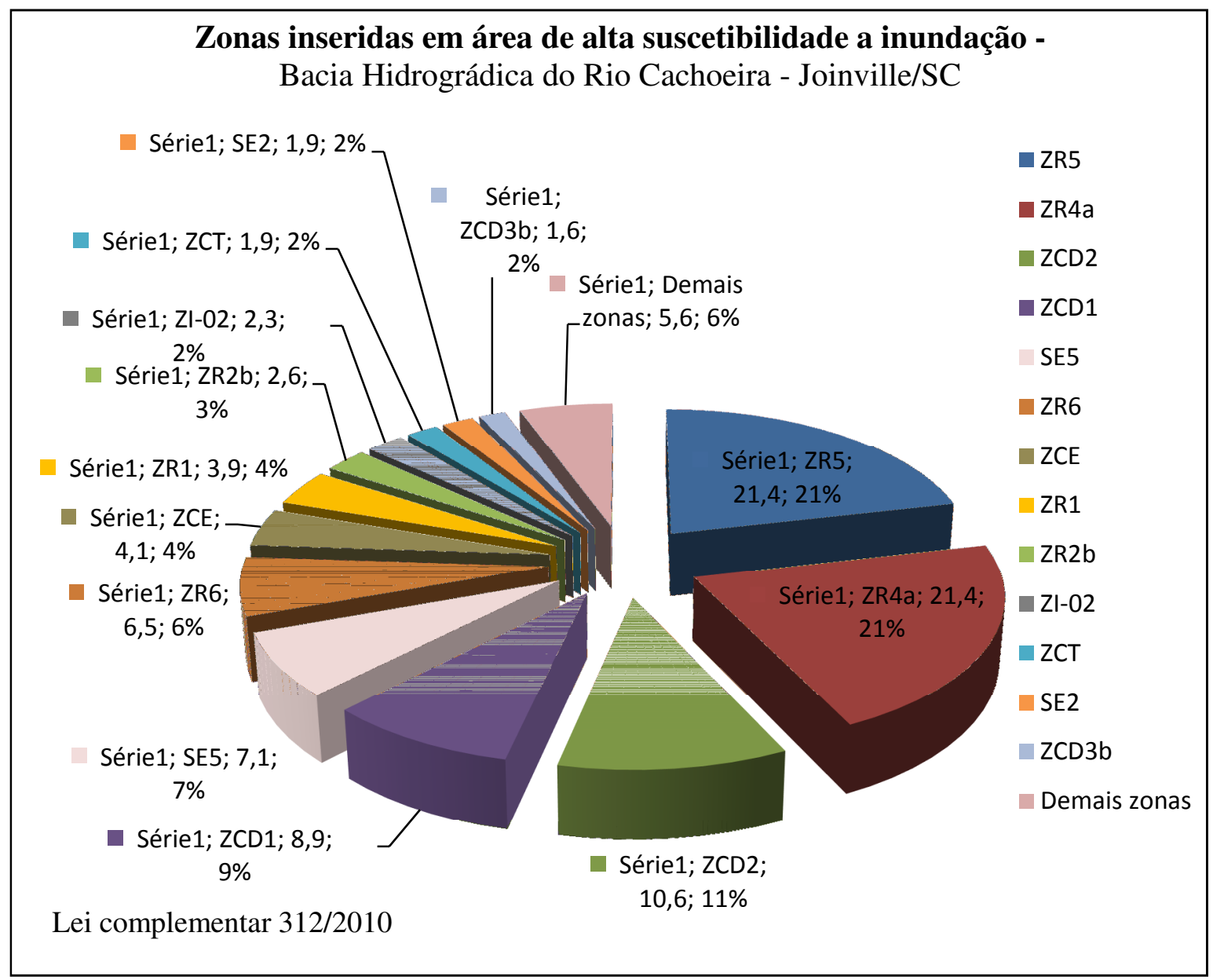

De acordo com os resultados apresentados, tem-se que $42 \%$ da área de suscetibilidade a inundação possui destinação de uso, estabelecida pelo zoneamento municipal, tanto em virtude da gênese quanto da infraestrutura atualmente existente, voltada predominantemente ao uso residencial (ZR5 e ZR4a). A terceira zona mais expressiva dentro da área de estudo insere-se na Zona de Corredor Diversificado - ZCD. Nesta área se concentram os usos residenciais, comerciais e de serviços, caracterizando-se como expansão da Zona Central, com centros comerciais à escala de bairro e com eixos comerciais ao longo de vias públicas.

Apesar da representatividade pequena quando comparada ao somatório das demais zonas inseridas em área de suscetibilidade a inundação, tem-se que 95\% da área designada como Zona Central, que destina-se preferencialmente às funções da administração pública, do comércio e serviços de âmbito geral, apresentando-se subdividida da seguinte forma: Zona Central Tradicional (ZCT) e Zona Central Expandida (ZCE), insere-se em área de risco. Este dado é de suma importância para a gestão da área, visto que os atos da municipalidade concentram-se neste local, bem como arquivos públicos, dentre outras documentações e atividades que afetam diretamente todo o município de Joinville/SC. 
Quanto aos instrumentos legais de ordenamento territorial da bacia hidrográfica do Rio Cachoeira, visto a problemática ligada a suscetibilidade a inundação, bem como a centralização de infraestruturas e serviços nesta área, o poder público vem realizando projetos, como o Plano Diretor de Drenagem Urbana - PDDU -, com vistas a identificar pontos críticos e soluções para mitigar os efeitos destes eventos. O PDDU apresenta uma série de propostas de intervenções para solucionar os problemas relacionados às inundações na área central da cidade, tendo como pressuposto que os efeitos adversos das inundações e alagamentos tendem a agravar-se com a intensificação da ocupação urbana.

Dentre os encaminhamentos do PDDU, tem-se a adoção conjunta de medidas estruturais e não estruturais. A calha principal do Rio Cachoeira é prioritária para a implantação das obras, pois a realização de obras nos afluentes aumentará a vazão no Rio Cachoeira, onde eles desaguam, o que traz o risco de mais inundações ao longo de sua calha. Sem que sejam resolvidos os problemas de cheia no rio principal, as obras realizadas nos afluentes não serão efetivas (JOINVILLE, 2011). Em caráter complementar, ações voltadas a minimizar os impactos da ocupação humana no meio ambiente também são contempladas, como a realização do zoneamento das áreas inundadas, controle da erosão do solo e assoreamento dos rios, incentivo a construções a prova de enchentes, incentivos fiscais para adoção de medidas que contribuam para o controle do escoamento superficial, dentre outras.

\section{Considerações finais}

Em consonância com a situação da área urbana de Joinville/SC, as inundações em áreas urbanas vem sendo alvo de intervenções e desenvolvimento de instrumentos de ordenamento territorial com vistas a mitigar os danos econômicos e sociais advindos da ocorrência destes eventos.

Várias são as causas atribuídas ao assentamento humano em áreas de risco no processo de urbanização, para o Ministério das Cidades, "a ausência ou a má aplicação de uma política pública de habitação e de desenvolvimento urbano levou boa parte da população a ocupar áreas ambientalmente frágeis, especialmente em margens de rios e encostas." (BRASIL, 2007).

O desenvolvimento do município de Joinville/SC é condizente com o que apresenta Tucci (2005) ao citar que devido à grande dificuldade de meios de transporte no passado, utilizava-se o rio como a via principal de deslocamento de pessoas e comercialização, no caso de Joinville o Rio Cachoeira, sendo que o desenvolvimento das cidades ocorreu às margens dos rios ou no litoral. Desta forma, mesmo existindo a fragilidade do ambiente local houve a fixação dos colonizadores em função de estratégias econômicas, condicionando o desenvolvimento da cidade e estabelecendo em área de risco sua zona central.

O cruzamento de informações junto aos dados de renda do município revelou que, em grande parte, as estruturas e população afetadas estão diretamente associadas à gênese do município, não sendo possível vincular, de acordo com os dados avaliados, baixa renda ao assentamento da população em áreas de risco a inundações. O fato de uma população com nível de renda mais elevado ocupar uma área de alto risco de inundação não é comum, visto que estes normalmente são ocupados pela população de menor poder aquisitivo, que por falta de alternativa historicamente ocupam áreas mais vulneráveis.

Em relação à análise dos instrumentos de ordenamento territorial da área de estudo, verifica-se a importância em adotar como unidade de planejamento a escala da bacia hidrográfica, conforme previsto pela Política Nacional de Recursos Hídricos, para melhor 
entendimento das inundações urbanas. Com isto, ressalta-se a importância da elaboração de instrumentos legais como o Plano Diretor de Drenagem Urbana desenvolvido para a bacia hidrográfica do Rio Cachoeira, tendo a função tanto de fornecer subsídio aos demais instrumentos de ordenamento territorial, quanto de avaliar estratégias de gestão destes eventos, detectando pontos críticos para intervenção com vistas a minimização de seus impactos, uma vez que a eliminação destes torna-se inviável em virtude da intensa urbanização da área.

\section{Referências}

BRASIL, Ministério das Cidades / Instituto de Pesquisas Tecnológicas - IPT Mapeamento de riscos em encostas e margem de rios / Celso Santos Carvalho, Eduardo Soares de Macedo e Agostinho Tadashi Ogura, organizadores - Brasília: Ministério das Cidades; Instituto de Pesquisas Tecnológicas - IPT, 2007. 176 p.

BRASIL, Ministério das Cidades. Estatuto das Cidades: Guia para implementação pelos municípios e cidadãos. Brasília: Ministério das Cidades, 2001.

FICKER, Carlos. História de Joinville: crônica da Colônia Dona Francisca. Joinville: Ed. Letradágua, 2008.

IPPUJ, Fundação Instituto de Pesquisa e Planejamento para o Desenvolvimento Sustentável de Joinville. Joinville em dados 2009. Joinville: Prefeitura Municipal, 2009. 164p.

MULLER, Cristiane Regina. Avaliação de suscetibilidade a inundações utilizando geotecnologias para a bacia hidrográfica do rio Cachoeira - Joinvile/SC. 2012. 124f. Dissertação (Mestrado Profissional em Planejamento Urbano e Análise Socioambiental) Universidade do Estado de Santa Catarina, Florianópolis, 2012.

PELUSO JUNIOR, Victor Antonio. Estudos de geografia urbana de Santa Catarina. Florianópolis: Ed. da UFSC, 1991. 400p.

ROCHA, Isa de Oliveira. Industrialização de Joinville - SC: da gênese às exportações. Florianópolis: [s.n.], 1997. 136p.

SILVEIRA, Wivian Nereida. KOBIYAMA, Masato. GOERL, Roberto Fabris. BRANDENBURG, Brigitte. História das Inundações em Joinville: 1851 - 2008. Curitiba: Ed. Organic Trading, 2009. 153p.

SOUZA, Luiz Alberto. A função social da propriedade e da cidade: entre a cidade do direito e o direito à cidade. Rio de Janeiro: UFRJ, 2005. Tese de Doutorado. Programa de Pós-Graduação em Planejamento Urbano e Regional, Universidade Federal do Rio de Janeiro.

TUCCI, C. E. M.. Gestão das inundações urbanas. Global Water Partnership. Edição em arquivo digital. Brasília, 2005.

XAVIER DA SILVA, J. Geoprocessamento para Análise Ambiental. Edição do Autor, RJ, 2001. 228p. 